\title{
Otomotiv endüstrisinde kullanılan DP450 ve DP800 saçlarında deformasyon hızının ve haddeleme yönünün çekme özelliklerine etkisi
}

\author{
Hakan AYDIN, Oğuz TUNCEL*, Muzaffer KARPUZ, Özgür AYDIN \\ Bursa Uludă̆ Üniversitesi, Mühendislik Fakültesi, Makine Mühendisliği Bölümü, Görükle Kampüsü, \\ Bursa
}

Geliș Tarihi (Recived Date): 22.05.2018

Kabul Tarihi (Accepted Date): 31.12 .2018

\section{Özet}

Çift fazlı DP (Dual Fazlı) çelikleri otomotiv sanayinde en çok tercih edilen çelik gruplarındandır. Kullanımları sırasında bu çeliklerin yükleme yönüne göre hadde yönü ve deformasyon hizı son derece önem arz etmektedir. Bu çalışmada, DP450 ve DP800 çift fazll çeliklerinde deformasyon hızı ve haddeleme yönüne bă̆lı olarak çekme sonuçları incelenmiștir. Deneysel çalışmalarda, haddeleme yönünün çekme ekseniyle yaptı̆̆ açılar $0^{\circ}, 45^{\circ}$ ve $90^{\circ}$, deformasyon hızları $2.4 \times 10^{-4}, 2.4 \times 10^{-3}, 2.4 \times 10^{-2}$ ve $1.2 \times 10^{-1}$ $s^{-1}$ olarak belirlenmiştir. Çalışmada elde edilen sonuçlar göstermiştir ki, DP450 ve DP800 çeliklerinde deformasyon hızının çekme özellikleri üzerindeki etkisi hadde yönü etkisinden daha fazla olmuştur. Her iki çelikte de deformasyon hızı artışı ile akma ve çekme mukavemeti değerleri artmış, kopma uzaması değerleri ise önemli ölçüde düşmüş̧ür. Ayrıca, her iki çelikte de deformasyon hızının akma mukavemeti üzerindeki etkisi çekme mukavemeti üzerindeki etkisinden daha fazla olmuştur. DP800 çeliğinde deformasyon hızı ile mukavemet artış oranı DP450 çeliğine nazaran daha düşük kalırken, kopma uzaması düşüş oranı ise daha fazla olmuştur. Hadde yönünün etkisine bakıldığında ise, DP450 ve DP800 çeliklerinde $45^{\circ}$ hadde yönünde nispeten daha yüksek mukavemet değerleri gözlenirken aynı hadde yönünde daha düşük uzama değerleri elde edilmiştir.

Anahtar Kelimeler: DP450 çeliği, DP800 çeliği, hadde yönü, deformasyon hızı, çekme özellikleri.

Hakan AYDIN, hakanay@uludag.edu.tr, http://orcid.org/0000-0001-7364-6281

*Oğuz TUNCEL, otuncel@uludag.edu.tr, https://orcid.org/0000-0002-6886-6367

Muzaffer KARPUZ, muzo1623@gmail.com, https://orcid.org/0000-0001-9804-6039

Özgür AYDIN, aydinozgur@ outlook.com.tr, https://orcid.org/0000-0002-4892-8583 


\title{
The effect of rolling direction and strain rate on the tensile properties of DP450 and DP800 steels used in the automotive industry
}

\begin{abstract}
Dual-phase steels are the most preferred steel group in the automotive industry. During their usage, rolling direction and strain rate of these steels with respect to rolling direction extremely important. In this study, the tensile test behaviors of DP450 and DP 800 dual phase steels were investigated depending on the strain rate and rolling direction. In the experimental studies the angles between rolling direction and tensile axis are $0^{\circ}, 45^{\circ}, 90^{\circ}$ and strain rates are determined as $2.4 \times 10^{-4}, 2.4 \times 10^{-3}, 2.4 \times 10^{-2}$ and $1.2 \times 10^{-1} \mathrm{~s}^{-1}$. The results obtained in the study showed that the deformation rate of DP450 and DP800 steels had a greater effect on the tensile properties than the rolling direction effect. In both alloys, the values of yield and tensile strength increased with the increase in deformation rate, and the values of percent fracture elongation decreased substantially. In addition, the effect of strain rate on yield strength is greater than the effect of strain rate on tensile strength of both steels. In the DP800 steel the rate of increase in tensile strength with the deformation rate is lower than the DP450 steel, while the decrease rate of the elongation rate is higher. When the effect of the rolling direction is considered, both DP450 and DP800 steels have the highest yield and tensile strengths in the $45^{\circ}$ rolling direction while both steels have lower elongation rates in the $45^{\circ}$ rolling direction.
\end{abstract}

Key Words: DP450 steel, DP800 steel, rolling direction, strain rate, tensile properties.

\section{Giriş}

Günümüzde, yüksek mukavemet ve yüksek şekil değiştirme özelliklerine sahip çift fazlı DP (Dual Fazlı) çeliklerinin otomotiv sektöründeki kullanımı oldukça yaygındır. Çift faz terimi bu çeliklerin sahip oldukları ferrit ve martenzit fazlarından gelmektedir. Çift fazlı düşük $\mathrm{C}$ oranına sahip bu çeliklerde, yumuşak ferrit matrisi içerisine dağılmış sert martenzit parçacıkları yüksek mukavemeti ve ferrit matrisi de yüksek şekil değiştirme özelliğini sağlamaktadır [1-4]. Çift fazlı çeliklerin üretimi ötektoid altı çeliklerin demir karbon denge diyagramında $\mathrm{Ac}_{1}-\mathrm{A}_{\mathrm{C} 3}$ sicaklıkları arasından yapısında bulunan östenitin martenzite dönüşebilecek hızlarda soğutulmasıyla mümkün olmaktadır. İstenilen mekanik özelliklerle birlikte dengeli bir çift fazlı çelik mikroyapısına ulaşmak için martenzitin hacimsel dağılımı ve bu dağılımı gerçekleştirmek için kritik sıcaklıklar arasında şekillendirme önemlidir. Termo-mekanik kontrollü (Thermomechanical Controlled Processing (TMCP)) olarak gerçekleştirilen bu işlem ferrit matrisi içerisine martenzit adacıklarının istenilen şekilde dağıtılmasını sağlamaktadır [5,6]. Haddeleme sırasında taneler hadde yönünde uzamakta ve belirli kristalografik doğrultularda yönlenmektedirler. Bunun sonucunda da DP çeliklerinde mekanik özellikler yöne bağlı hale gelir ve farklı doğrultularda farklı mekanik özellikler ortaya çıkar: Uygulanan kuvvet doğrultusunun hadde yönüne göre durumu DP çeliklerinin mekanik özelliklerini etkiler [7,8]. Ayrıca, genellikle metallerde deformasyon hızındaki artışla birlikte akma ve çekme mukavemetlerinin arttığı buna karşın yüzde uzama değerlerinin azaldığ 
bilinmektedir. Özellikle, hacim merkezli kübik (HMK) kafes yapısına sahip metallerde deformasyon hızındaki artış mekanik özellikler üzerinde daha etkilidir [9]. Bu bağlamda, otomotiv sanayinde kullanılan çelik sacların mekanik özelliklerinin deformasyon hızı ve hadde yönü ile değişiminin tespit edilmesi teknolojik açıdan önem arz etmektedir.

DP çeliklerde deformasyon oranının ve hadde yönünün çekme özelliklerine etkileri üzerine çeşitli çalışmalar yapılmıştır. Yu ve ark. [10] DP600 çeliklerinde $10^{-4}-1600 \mathrm{~s}^{-1}$ arasında çeşitli deformasyon oranlarında akma ve çekme mukavemetlerindeki değişimi tespit etmişlerdir. Deformasyon oranındaki artışla beraber akma ve çekme mukavemetleri artmıştır. Özellikle akma mukavemetinde deformasyon oranındaki artışla birlikte yüksek olarak görülen \%100'lük bir artış olmuştur. Kim ve ark. [11] DP780, DP980 ve TRIP780 çeliklerinde deformasyon hızındaki $0.1 \mathrm{~s}^{-1}-500 \mathrm{~s}^{-1}$ arasındaki değişimin çekme özelliklerine etkilerini incelemişlerdir. Deformasyon hadde yönü, hadde yönüne dik ve diyagonal olmak üzere 3 farklı yönde gerçekleștirilmiştir. Deformasyon oranı arttırıldığında akma ve çekme mukavemetlerinin arttı̆̆ görülmüştür. Curtze ve ark. [12] DP600 ve TRIP700 çeliklerinde sicaklık ve deformasyon hızındaki değişimin mekanik özelliklere olan etkilerini araştırmışlardır. Çalışmalarında mekanik özellikleri belirlemek için gerçekleştirdikleri çekme testleri sirasında $-100<\mathrm{T}<235^{\circ} \mathrm{C}$ aralığında değișen ortam sicaklıkları ve $10^{-3} \mathrm{~s}^{-1}$ ile $1250 \mathrm{~s}^{-1}$ aralığında değişen deformasyon oranlarını seçmişlerdir. $\mathrm{Bu}$ çalışma sonucunda, deformasyon oranı değiş̧iminden DP çeliklerinin, sıcaklık değişiminden ise TRIP çeliklerinin daha fazla etkilendiği rapor edilmiştir.

Literatür çalışmaları incelendiğinde DP450 ve DP800 çeliklerinin deformasyon oranı ve hadde yönüyle mekanik özellik değişimleri üzerine yok denecek kadar az çalışmanın olduğu ve konunun netliğe kavuşmadığı belirlenmiştir. Bu eksiklik çalışmanın yapılmasına dayanak oluşturmuştur. Bu çalışmada, DP450 ve DP800 çeliklerinin deformasyon hızının ve haddeleme yönünün malzemenin mekanik özelliklerine etkilerinin incelenmesi amacıyla 4 farklı deformasyon hızında $\left(2.4 \times 10^{-4}, 2.4 \times 10^{-3}\right.$, $2.4 \times 10^{-2}$ ve $\left.1.2 \times 10^{-1} \mathrm{~s}^{-1}\right)$ ve 3 farklı haddeleme yönünde $\left(0^{0}, 45^{0}, 90^{0}\right)$ çekme testleri yapılmıştır. Deformasyon hızının ve haddeleme yönünün malzemenin mekanik özelliklerine (akma mukavemeti, çekme mukavemeti ve kopma uzaması) etkileri deneysel olarak incelenmiştir.

\section{Materyal ve metod}

Çalışmada kullanılan DP450 ve DP800 çeliklerinin kimyasal özellikleri Tablo 1'de verilmiştir. DP450 ve DP800 çelikleri 1x1000x1000 mm ebatlarında sac şeklinde ticari olarak temin edilmiştir. Bu levhalardan haddeleme yönü ile çekme ekseni arasındaki $0^{\circ}$, $45^{\circ}$ ve $90^{\circ}$ 'lik açılarda giyotin makas ile kesilerek dikdörtgen kesitli numuneler hazırlanmıştır (Şekil 1). Sonrasında hazırlanan numuneler uçlarından gruplar halinde kaynaklanıp tel erezyon işlemi kullanılarak ASTM-E8 standardına göre çekme numuneleri hazırlanmıştır (Şekil 2).

Çekme testleri, Uludağ Üniversitesi Makine Mühendisliği Bölümü Malzeme ve Mekanik Test Laboratuvarında tamamen bilgisayar kontrollü $250 \mathrm{kN}$ kapasiteli UTEST7014 çekme cihazında oda sıcaklığında $2.4 \times 10^{-4}, 2.4 \times 10^{-3}, 2.4 \times 10^{-2}$ ve $1.2 \times 10^{-1} \mathrm{~s}^{-}$ ${ }^{1}$ deformasyon hızlarında gerçekleştirilmiştir. Tek eksenli çekme testleri uygulanmış olup uzama ölçümlerinde otomatik uzama-ölçer (ekstansometre) kullanılmıştır. Çekme 
testlerinden akma mukavemeti, çekme mukavemeti ve kopma uzaması değerleri elde edilmiştir. Çalışmada kullanılan DP çeliklerinin belirgin bir akma göstermemesinden dolayı \%0.2'lik plastik uzama değerine karşılık gelen gerilme değeri, akma dayanımı olarak alınmıştır $\left(\mathrm{Rp}_{0.2}\right)$. Her bir numune için en az 3 adet çekme testi uygulanmış olup, numunelerin çekme değerleri olarak ortalama değerler belirlenmiştir.

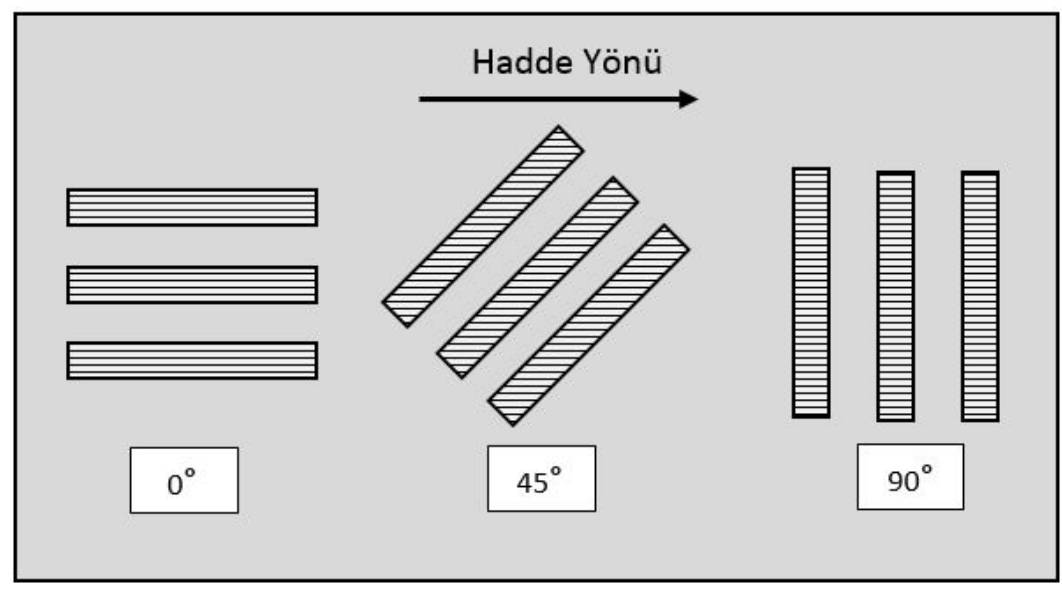

Şekil 1. DP450 ve DP800 çeliklerinden $0^{\circ}, 45^{\circ}$ ve $90^{\circ}$ lik açılarda giyotin makas ile kesilerek hazırlanan dikdörtgen kesitli numuneler.

Tablo 1. Çalışmada kullanılan çeliklerin kimyasal bileşimleri (\% ağırlık).

\begin{tabular}{cccc}
\hline Çelik & $\begin{array}{c}\mathrm{C} \\
\max .\end{array}$ & $\begin{array}{c}\mathrm{Mn} \\
\max .\end{array}$ & $\begin{array}{c}\mathrm{Si} \\
\max .\end{array}$ \\
\hline $\mathrm{DP} 450$ & 0.08 & 1.6 & 0.4 \\
\hline $\mathrm{DP} 800$ & 0.17 & 2.2 & 0.6 \\
\hline
\end{tabular}

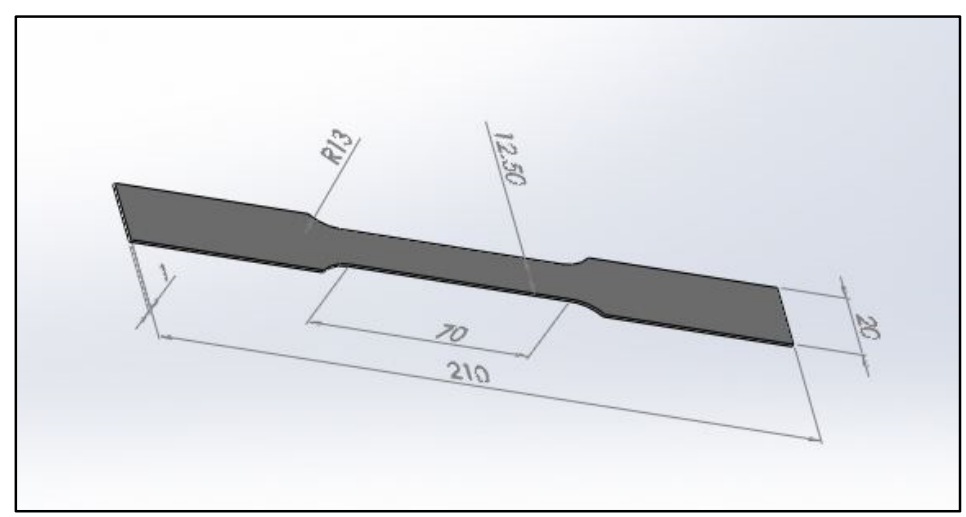

Şekil 2. Standartlara göre hazırlanan çekme testi numunesi [13]. 


\section{Sonuçlar ve tartışma}

Farklı hadde yönlerinde DP450 çeliğine ait numunelerin farklı deformasyon hızlarında yapılan çekme test sonuçları Tablo 2'de verilmiştir. İlgili sonuçların grafiksel gösterimleri de (x-ekseni logaritmik) Şekil 3-5 arasında görülmektedir. Deformasyon hızı artışıyla mukavemet değerleri artarken uzama değerleri düşmektedir (Şekil 3-5). Deformasyon hızının $2.4 \times 10^{-4} \mathrm{~s}^{-1}$ den $1.2 \times 10^{-1} \mathrm{~s}^{-1} \mathrm{e}$ çıkarılmasıyla; çekme dayanımı $0^{\circ}$ hadde yönünde $\% 5.23,45^{\circ}$ hadde yönünde $\% 4.37,90^{\circ}$ hadde yönünde $\% 4.64$, akma dayanımı $0^{\circ}$ hadde yönünde $\% 18.84,45^{\circ}$ hadde yönünde $\% 21.19,90^{\circ}$ hadde yönünde $\% 14.51$ artmıștır. Görüldüğü gibi deformasyon hızı akma mukavemeti üzerinde daha etkin olmuştur. Nitekim, deformasyon hızının mukavemet üzerindeki etkisi dislokasyonlar üzerinden gerçekleşmektedir: Deformasyon hızı artışı ile dislokasyon hareketi nispeten zorlaşmaktadır veya gecikmektedir. Buna istinaden, deformasyon hızının elastik bölgeden plastik bölgeye (dislokasyon hareketinin gerçekleşmeye başlaması) geçiş noktası olan akma mukavemetine etkisinin de belirgin olacağı açıtır. Diğer taraftan, deformasyon hızının $2.4 \times 10^{-4} \mathrm{~s}^{-1}$ den $1.2 \times 10^{-1} \mathrm{~s}^{-1} \mathrm{e}$ çıkarılmasıyla; kopma uzaması $0^{\circ}$ hadde yönünde $\% 18.8,45^{\circ}$ hadde yönünde $\% 25.54$ ve $90^{\circ}$ hadde yönünde \%20.01 düşmüştür. Deformasyon hızının kopma uzaması üzerindeki etkisi de çok belirgin olmuştur. Özellikle, DP saclarının otomotiv sanayindeki soğuk şekillendirme işlemlerinde meydana gelebilecek çatlama ve yırtılmada bu hususa dikkat edilmesi gerekebilir. Genel olarak, DP450 sacında, $45^{\circ}$ hadde yönünde daha yüksek mukavemet değerleri elde edilirken aynı hadde yönünde daha düşük uzama değerleri tespit edilmiştir (Şekil 6-8). DP450 çeliğinde en yüksek mukavemet değerleri ve en düşük kopma uzaması $45^{\circ}$ hadde yönünde $1.2 \times 10^{-1} \mathrm{~s}^{-1}$ deformasyon hızında görülmüştür. Genel itibariyle, aynı çelikte, $0^{\circ}$ hadde yönü ile $90^{\circ}$ hadde yönü karşılaştırıldığında, $90^{\circ}$ hadde yönündeki mukavemet ve kopma uzaması değerlerinin ise nispeten daha düşük olduğu söylenebilir.

Tablo 2. DP450 çeliğinin çekme testi sonuçları (ortalama değerler).

\begin{tabular}{|c|c|c|c|c|c|c|c|}
\hline $\begin{array}{c}\text { Hadde } \\
\text { Yönüi }\end{array}$ & $\begin{array}{c}\text { Deformasyon } \\
\mathrm{Hizl}^{-1} \\
{\left[\mathrm{~s}^{-1}\right]}\end{array}$ & $\begin{array}{c}\text { Çekme } \\
\text { Dayanımı } \\
\text { Rm [MPa] }\end{array}$ & $\begin{array}{c}\text { Standart } \\
\text { Sapma }\end{array}$ & $\begin{array}{c}\text { Akma } \\
\text { Dayanımı } \\
\text { Rpo,2 [MPa] }\end{array}$ & $\begin{array}{c}\text { Standart } \\
\text { Sapma }\end{array}$ & $\begin{array}{c}\text { Kopma } \\
\text { Uzaması } \\
\text { A [\%] }\end{array}$ & $\begin{array}{c}\text { Standart } \\
\text { Sapma }\end{array}$ \\
\hline \multirow{4}{*}{$0^{\circ}$} & $2.4 \times 10^{-4}$ & 478 & 0 & 295.35 & 1.41 & 32.45 & 0.91 \\
\hline & $2.4 \times 10^{-3}$ & 485.5 & 0.7 & 305.09 & 9.19 & 28.95 & 0.21 \\
\hline & $2.4 \times 10^{-2}$ & 496.3 & 3.05 & 318.76 & 7.81 & 26.97 & 0.12 \\
\hline & $1.2 \times 10^{-1}$ & 503 & 1.41 & 351 & 5.66 & 26.35 & 1.63 \\
\hline \multirow{4}{*}{$45^{\circ}$} & $2.4 \times 10^{-4}$ & 488 & 0 & 296.5 & 4.95 & 31.25 & 0.64 \\
\hline & $2.4 \times 10^{-3}$ & 492.67 & 2.08 & 315.23 & 3.54 & 27.04 & 0.72 \\
\hline & $2.4 \times 10^{-2}$ & 500.34 & 0.58 & 329.84 & 2.89 & 25.8 & 0.36 \\
\hline & $1.2 \times 10^{-1}$ & 509.34 & 1.15 & 359.33 & 4.95 & 23.27 & 2.26 \\
\hline \multirow{4}{*}{$90^{\circ}$} & $2.4 \times 10^{-4}$ & 477.5 & 2.12 & 298.5 & 3.54 & 32.2 & 0 \\
\hline & $2.4 \times 10^{-3}$ & 481.67 & 2.31 & 302.35 & 2.83 & 28.2 & 0 \\
\hline & $2.4 \times 10^{-2}$ & 489 & 1 & 312 & 4.24 & 27.13 & 0.46 \\
\hline & $1.2 \times 10^{-1}$ & 499.67 & 0.58 & 341.8 & 2.55 & 25.73 & 0.9 \\
\hline
\end{tabular}




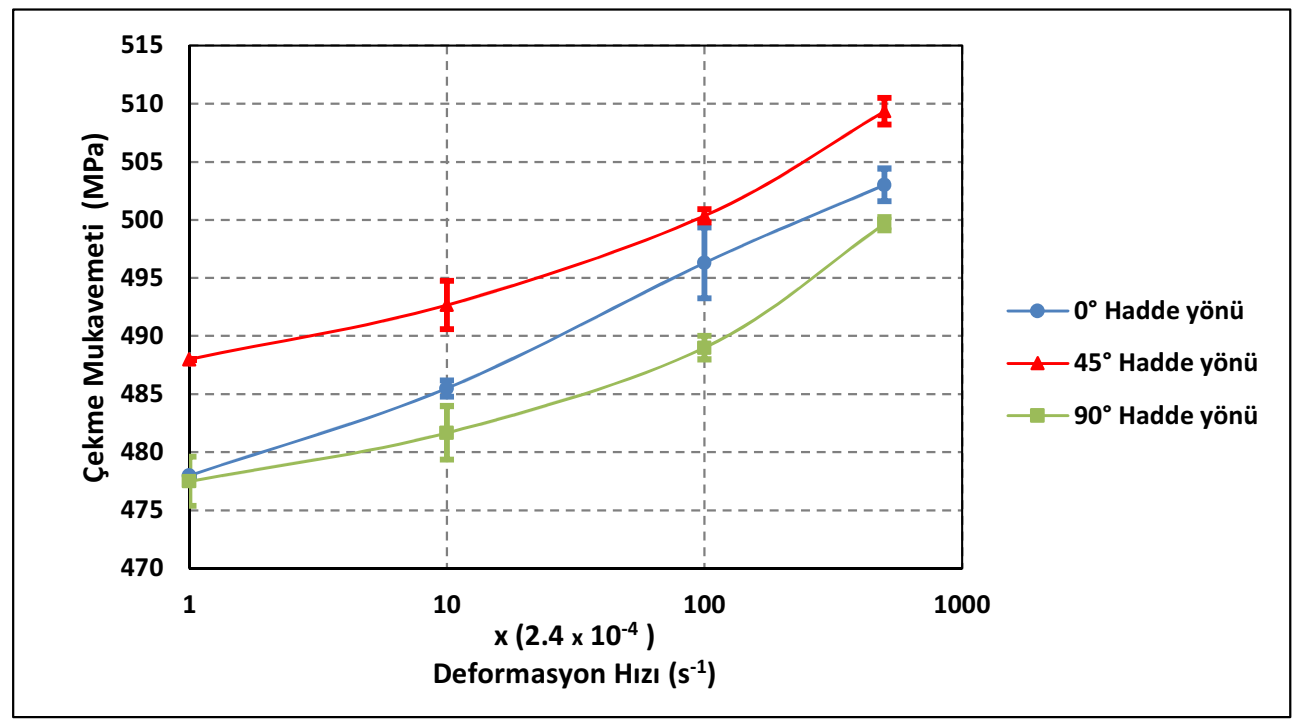

Şekil 3. DP450 çeliğinde hadde yönüne bağlı olarak çekme mukavemetinin deformasyon hızı ile değişimi.

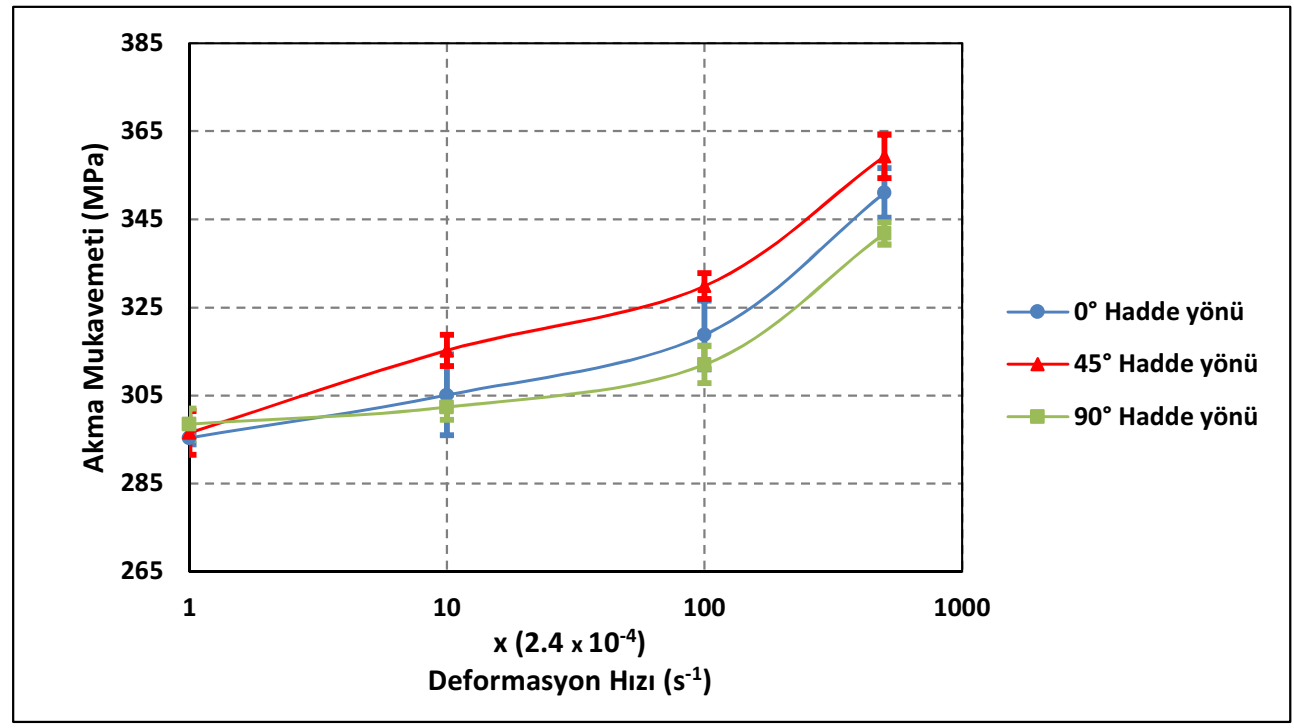

Şekil 4. DP450 çeliğinde hadde yönüne bağlı olarak akma mukavemetinin deformasyon hızı ile değişimi. 


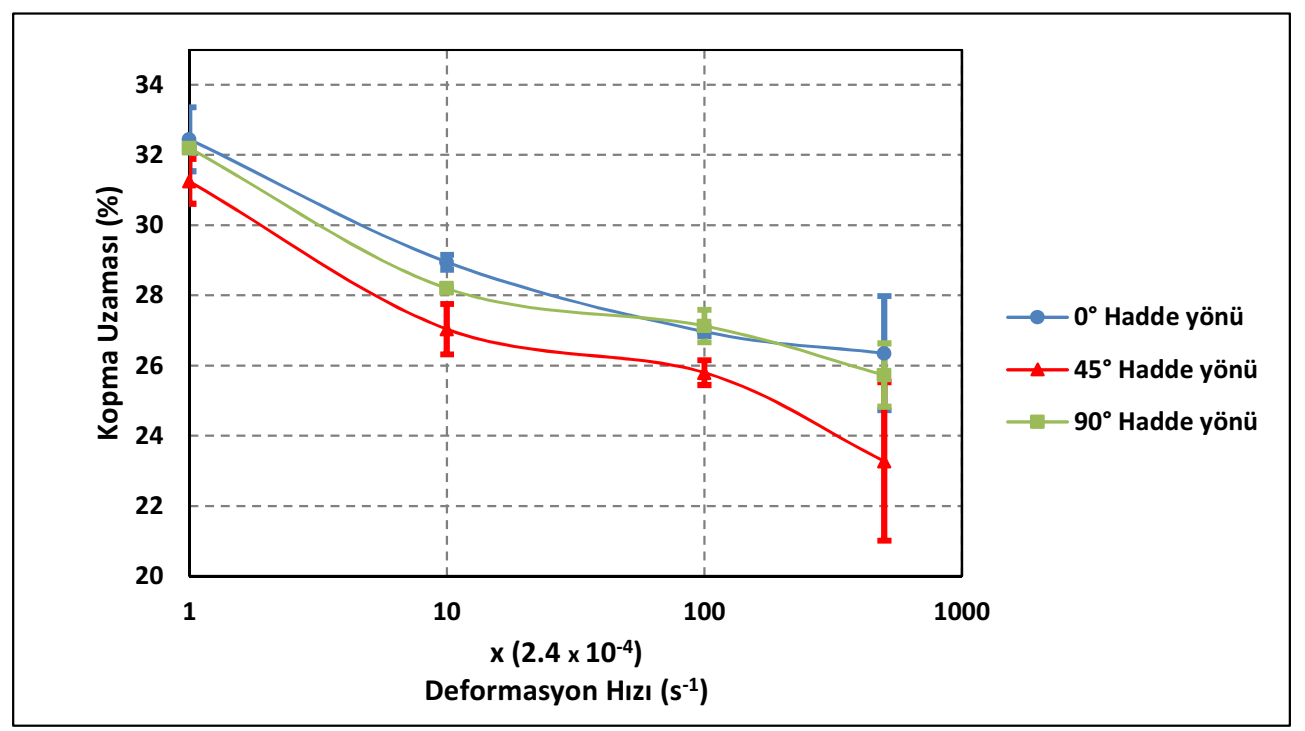

Şekil 5. DP450 çeliğinde hadde yönüne bağlı olarak kopma uzamasının deformasyon hızı ile değişimi.

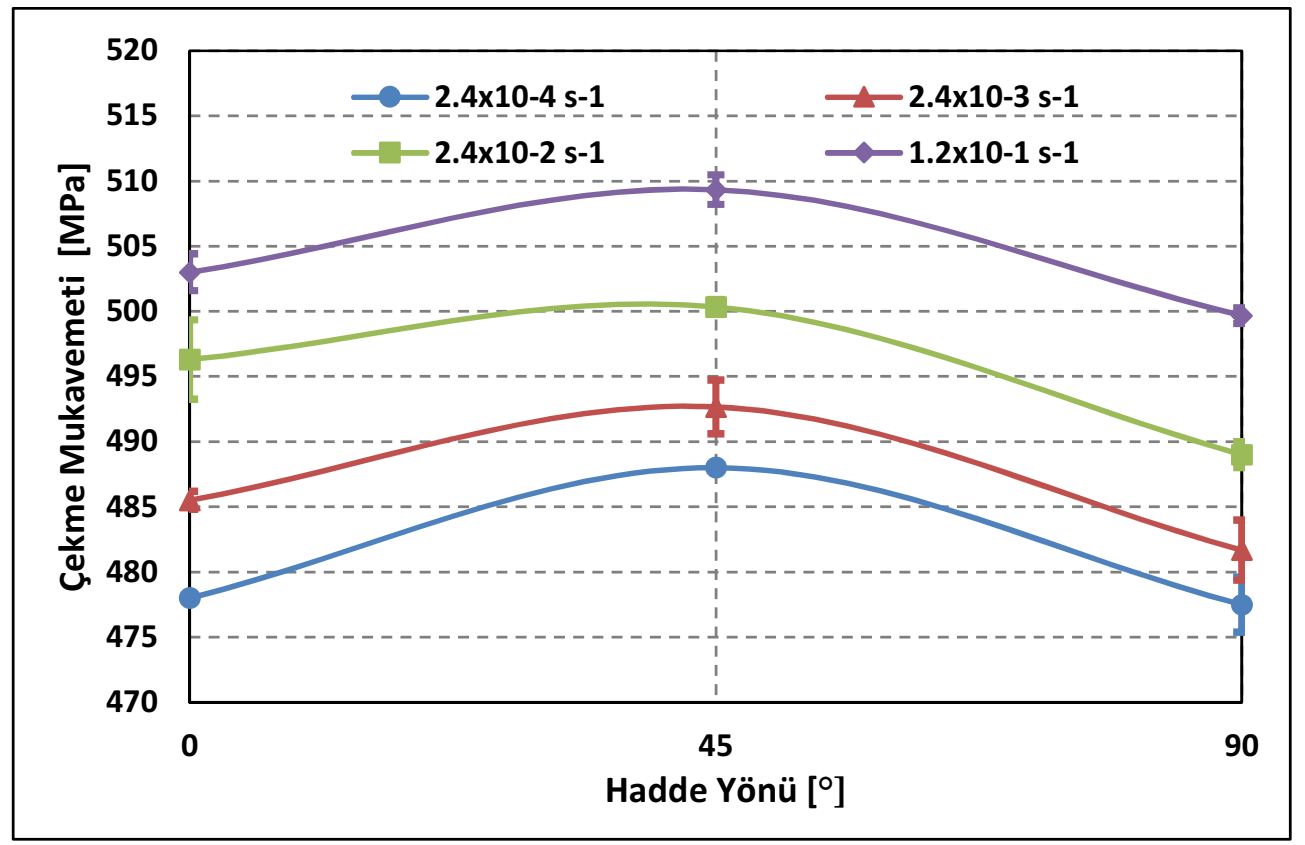

Şekil 6. Farklı deformasyon hızlarında DP450 çeliğine ait numunelerde çekme mukavemetinin hadde yönü ile değișimi. 


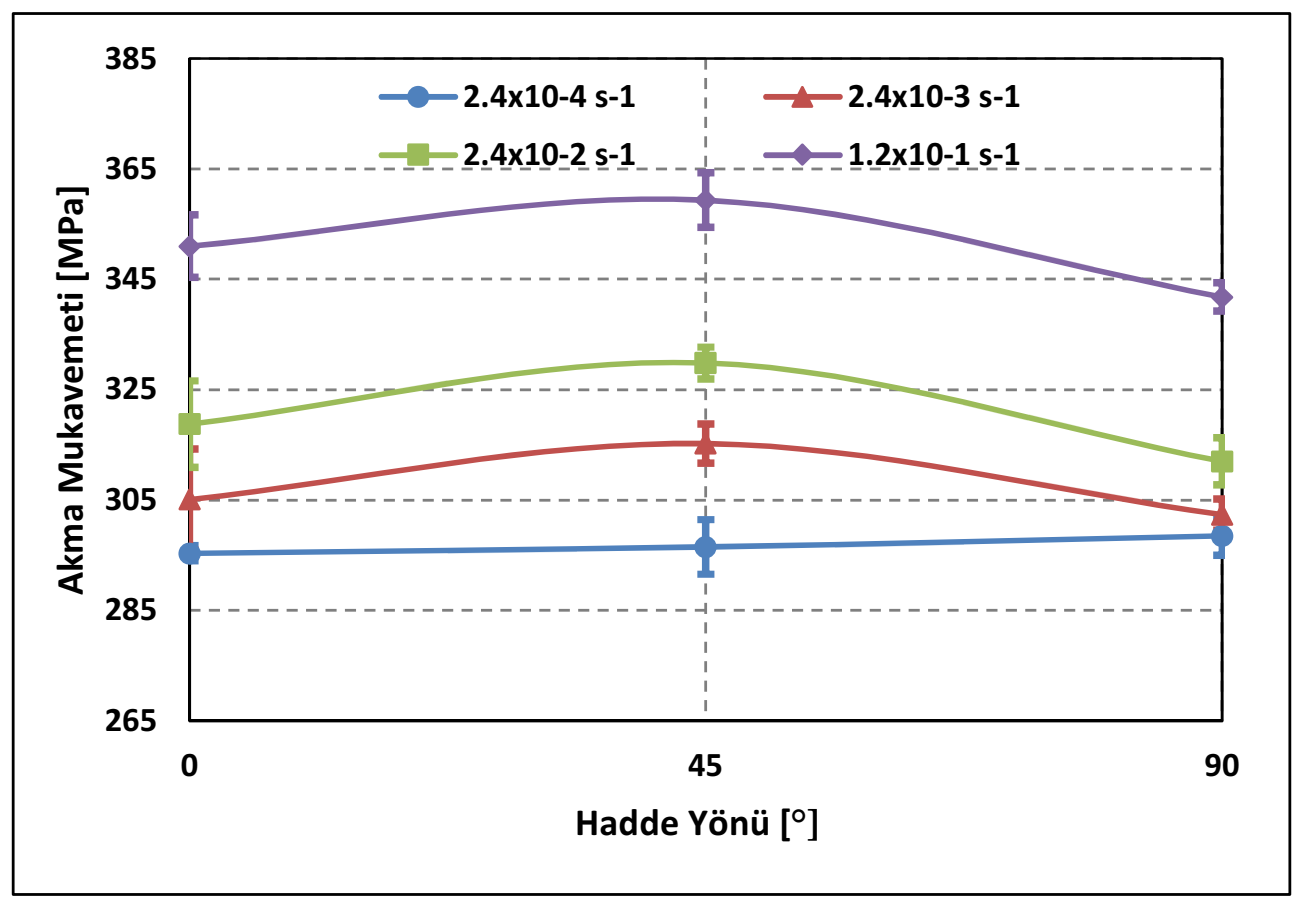

Şekil 7. Farklı deformasyon hızlarında DP450 çeliğine ait numunelerde akma mukavemetinin hadde yönü ile değişimi.

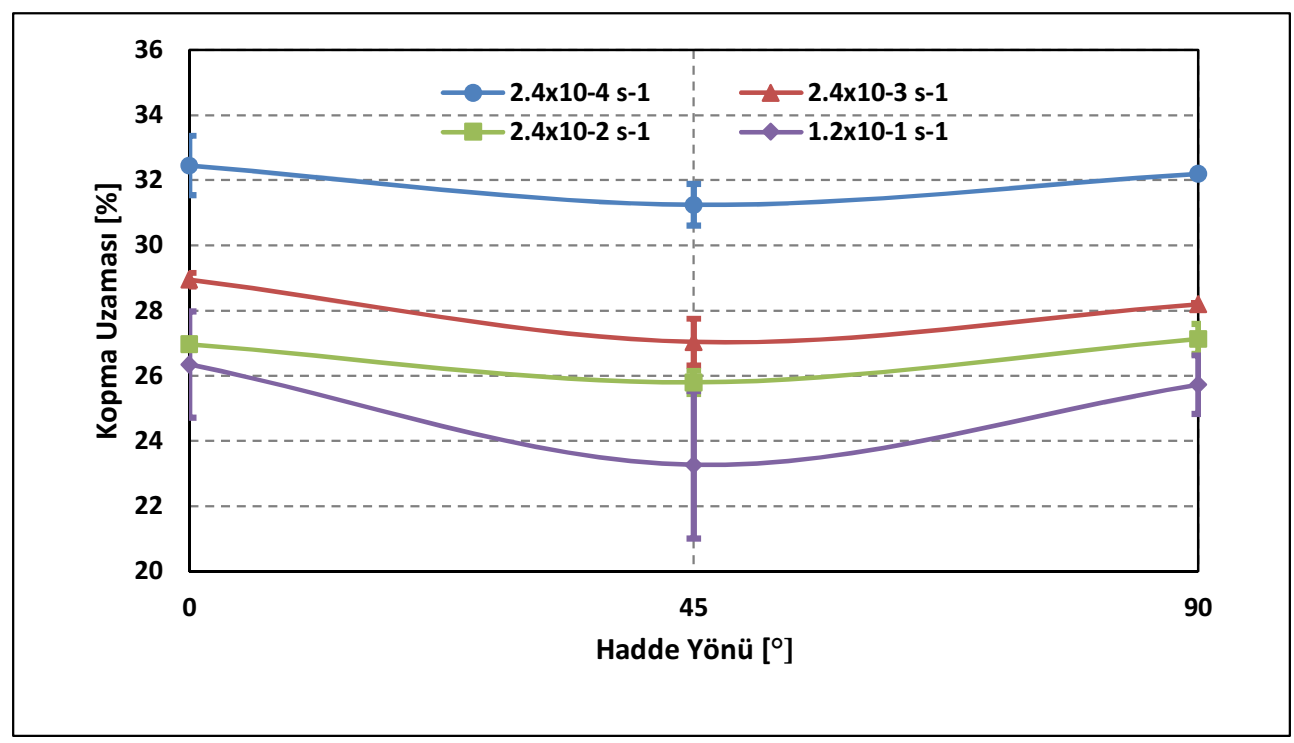

Şekil 8. Farklı deformasyon hızlarında DP450 çeliğine ait numunelerde kopma uzamasının hadde yönü ile değişimi.

Farklı hadde yönlerinde DP800 çeliğine ait numunelerin ise farklı deformasyon hızlarında yapılan çekme test sonuçları Tablo 3'te verilmiştir. İlgili sonuçların grafiksel gösterimleri de (x-ekseni logaritmik) Şekil 9-11 arasında görülmektedir. DP450 çeliğine benzer şekilde, DP800 çeliğinin deformasyon hızıyla mukavemet değerleri artarken 
uzama değerleri düșmektedir (Șekil 9-11). Deformasyon hızının $2.4 \times 10^{-4} \mathrm{~s}^{-1}$ den $1.2 \times 10^{-}$ ${ }^{1} \mathrm{~s}^{-1}$ e çıkarılmasıyla; çekme dayanımı $0^{\circ}$ hadde yönünde $\% 1.83,45^{\circ}$ hadde yönünde $\% 3.11,90^{\circ}$ hadde yönünde $\% 1.97$, akma dayanımı $0^{\circ}$ hadde yönünde $\% 15.89,45^{\circ}$ hadde yönünde $\% 17.21,90^{\circ}$ hadde yönünde $\% 14.14$ oranında artmıștır. Deformasyon hızının DP800 çeliğinin akma mukavemeti üzerindeki etkisi DP450 çeliğindeki gibi çok belirgin iken çekme mukavemeti üzerindeki etkisi çok sınırlı kalmıştır (neredeyse ihmal edilebilir düzeydedir). Esasen, DP800 çeliğinde deformasyon hızı ile mukavemet artış oranı DP450 çeliği ile karşılaştırıldığında nispeten daha düşük kalmıştır. Bu da, DP800 çeliği içerisindeki martenzit oranın daha fazla olması ile ilişkilendirilebilir: Martenzit fazının hali hazırda dislokasyon hareketlerini engelleyici rol oynaması dislokasyon hareketlerinin deformasyon hızı ile etkileşimini nispeten baskılamıştır. Diğer taraftan, deformasyon hizının $2.4 \times 10^{-4}$ ten $1.2 \times 10^{-1} \mathrm{~s}^{-1}$ 'e çıkarılmasıyla; kopma uzaması $0^{\circ}$ hadde yönünde $\% 31.84,45^{\circ}$ hadde yönünde $\% 23.84$, ve $90^{\circ}$ hadde yönünde $\% 31.89$ düşmüştür. Deformasyon hızının kopma uzaması üzerindeki etkisi DP450 çeliğinden de fazla olmuştur. DP800 çeliğinde hadde yönü etkisine bakıldığında ise, DP450 çeliğine benzer şekilde $45^{\circ}$ hadde yönünde daha yüksek mukavemet değerleri elde edilirken aynı hadde yönünde daha düşük uzama değerleri tespit edilmiştir (Şekil 12-14). En yüksek akma ve çekme mukavemeti değerlerine $45^{\circ}$ hadde yönünde $1.2 \times 10^{-1} \mathrm{~s}^{-1}$ deformasyon hızında 575.5 MPa ve $846 \mathrm{MPa}$ ile ulaşılmıştır. Aynı çelikte, $0^{\circ}$ hadde yönü ile $90^{\circ}$ hadde yönü karşılaştırıldığında, $90^{\circ}$ hadde yönündeki mukavemet değerleri nispeten daha yüksek iken, kopma uzaması değerleri ise nispeten daha düşüktür.

Tablo 3. DP800 çeliğinin çekme testi sonuçları (ortalama değerler).

\begin{tabular}{|c|c|c|c|c|c|c|c|}
\hline $\begin{array}{c}\text { Hadde } \\
\text { Yönü }\end{array}$ & $\begin{array}{c}\text { Deformasyon } \\
\text { Hizl } \\
{\left[\mathbf{s}^{-1}\right]}\end{array}$ & $\begin{array}{c}\text { Çekme } \\
\text { Dayanımı } \\
\text { Rm [MPa] }\end{array}$ & $\begin{array}{c}\text { Standart } \\
\text { Sapma }\end{array}$ & $\begin{array}{c}\text { Akma } \\
\text { Dayanımı } \\
\text { Rpo,2 [MPa] }\end{array}$ & $\begin{array}{c}\text { Standart } \\
\text { Sapma }\end{array}$ & $\begin{array}{c}\text { Kopma } \\
\text { Uzaması } \\
\text { A [\%] }\end{array}$ & $\begin{array}{c}\text { Standart } \\
\text { Sapma }\end{array}$ \\
\hline \multirow{4}{*}{$\mathbf{0}^{\circ}$} & $2.4 \times 10^{-4}$ & 820.5 & 6.36 & 474.18 & 4.95 & 20.1 & 0.14 \\
\hline & $2.4 \times 10^{-3}$ & 823.5 & 0.7 & 482.73 & 0.71 & 17.5 & 0 \\
\hline & $2.4 \times 10^{-2}$ & 827 & 5.2 & 511.33 & 8.5 & 16.97 & 0.4 \\
\hline & $1.2 \times 10^{-1}$ & 835.5 & 0.71 & 549.53 & 8.56 & 13.7 & 0.14 \\
\hline \multirow{4}{*}{$45^{\circ}$} & $2.4 \times 10^{-4}$ & 820.5 & 7.78 & 491 & 1.41 & 17.95 & 0.35 \\
\hline & $2.4 \times 10^{-3}$ & 826.34 & 1.53 & 498.67 & 0.58 & 17 & 0.17 \\
\hline & $2.4 \times 10^{-2}$ & 833.5 & 3.87 & 537 & 3.83 & 16.18 & 0.72 \\
\hline & $1.2 \times 10^{-1}$ & 846 & 1.41 & 575.5 & 7.07 & 13.67 & 0.42 \\
\hline \multirow{4}{*}{$90^{\circ}$} & $2.4 \times 10^{-4}$ & 824.5 & 0.71 & 496 & 0 & 18.5 & 0.42 \\
\hline & $2.4 \times 10^{-3}$ & 825 & 5.85 & 501.5 & 6.11 & 17.48 & 0.47 \\
\hline & $2.4 \times 10^{-2}$ & 831.67 & 2.08 & 534.33 & 6.35 & 16.07 & 0.4 \\
\hline & $1.2 \times 10^{-1}$ & 840.75 & 2.63 & 566.15 & 7.07 & 12.6 & 0.88 \\
\hline
\end{tabular}




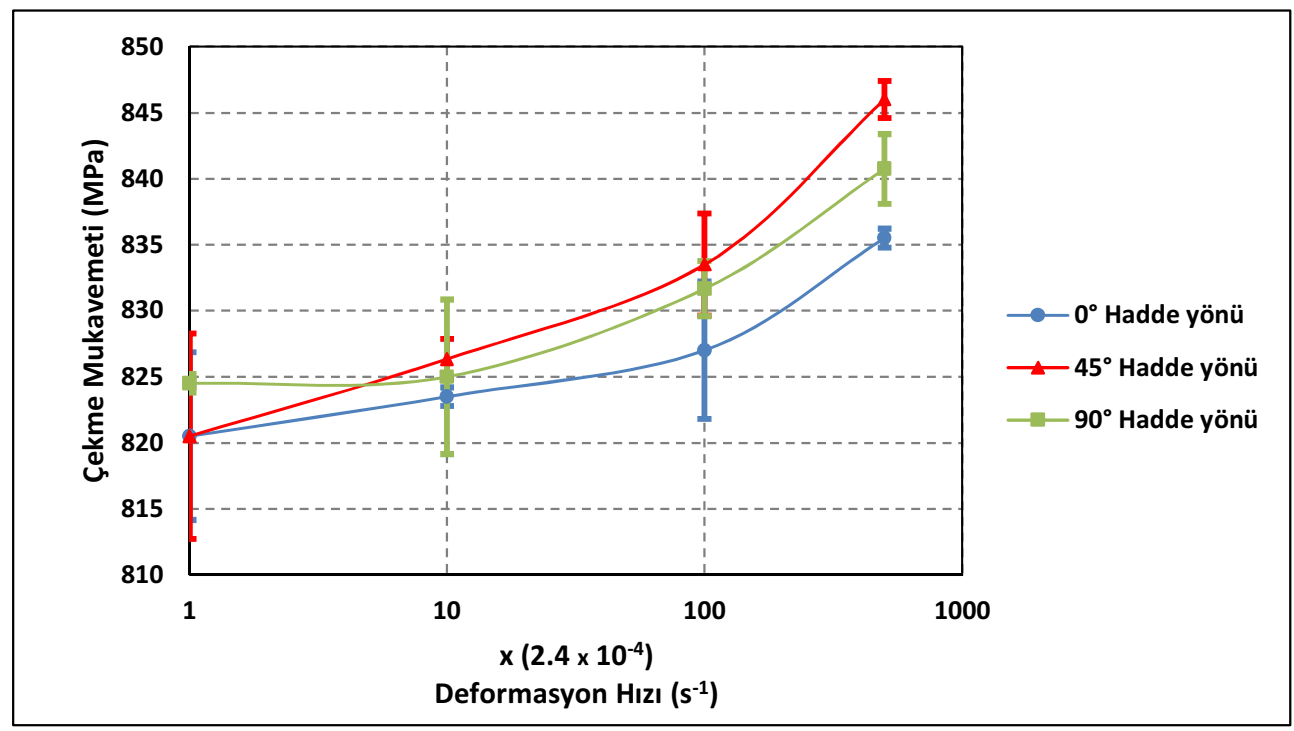

Şekil $9.0^{\circ}, 45^{\circ}$ ve $90^{\circ}$ hadde yönünde DP800 çeliğine ait numunelerde çekme mukavemetinin deformasyon hızı ile değişimi.

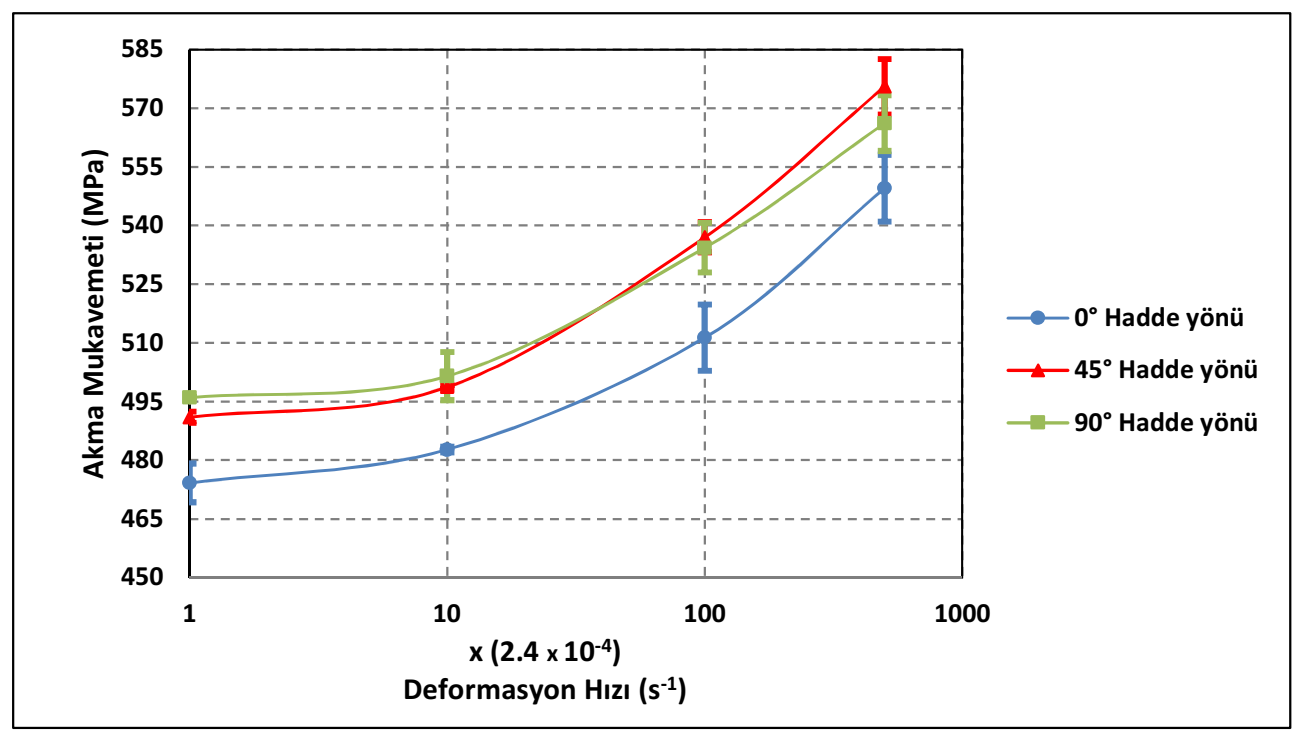

Şekil $10.0^{\circ}, 45^{\circ}$ ve $90^{\circ}$ hadde yönünde DP800 çeliğine ait numunelerde akma mukavemetinin deformasyon hızı ile değișimi. 


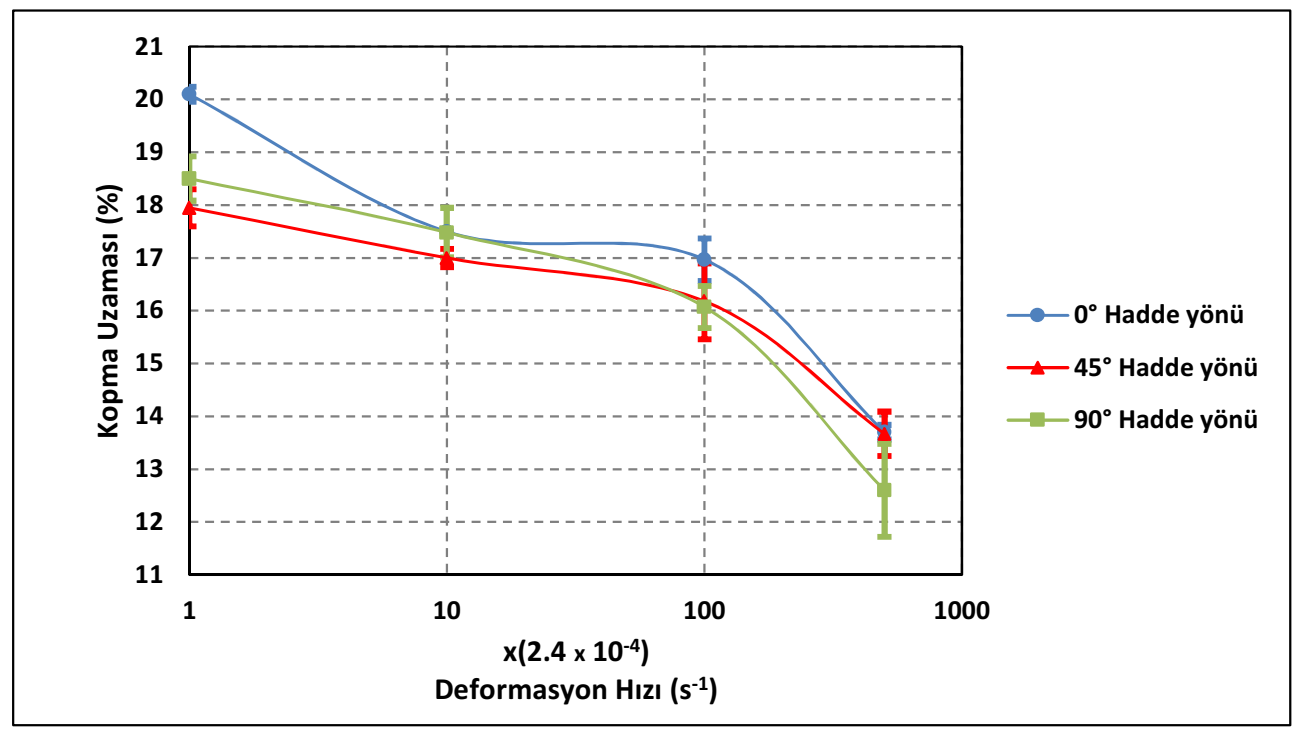

Şekil $11.0^{\circ}, 45^{\circ}$ ve $90^{\circ}$ hadde yönünde DP800 çeliğine ait numunelerde yüzde kopma uzamasının deformasyon hızı ile değişimi.

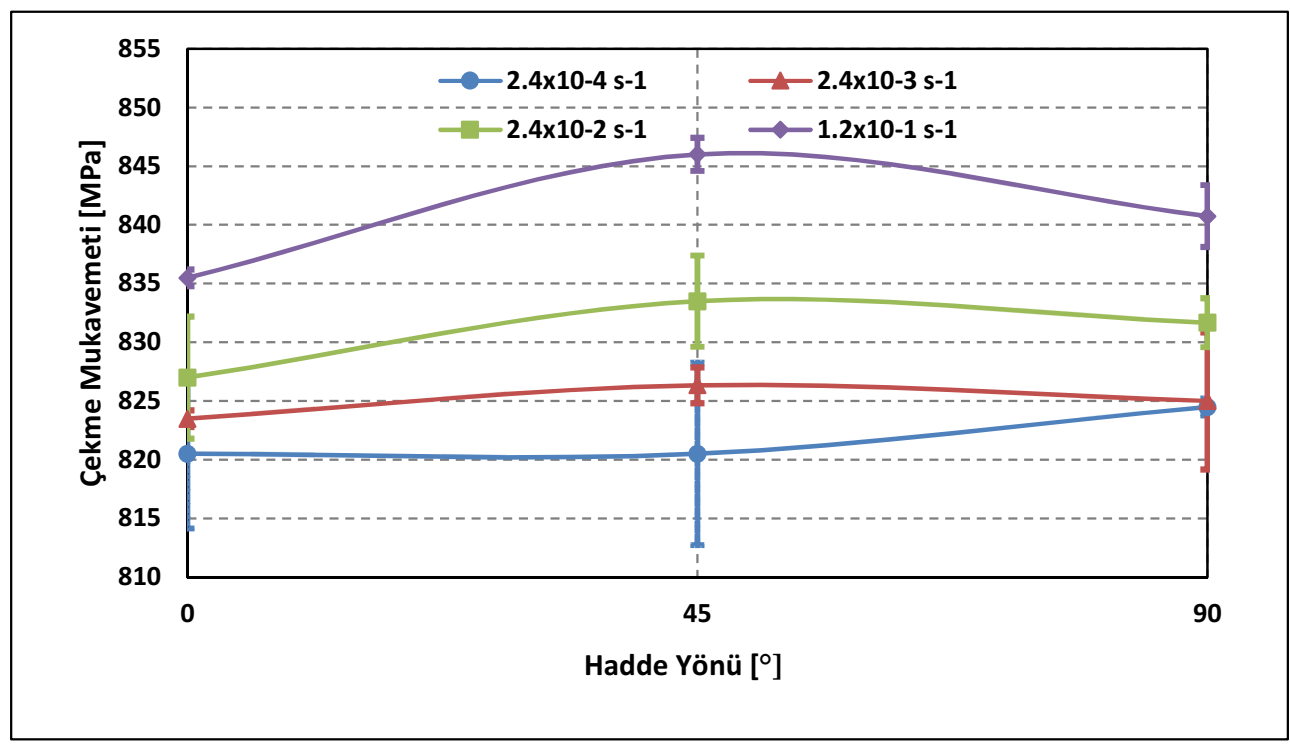

Şekil 12. Farklı deformasyon hızlarında DP800 çeliğine ait numunelerde çekme mukavemetinin hadde yönü ile değişimi. 


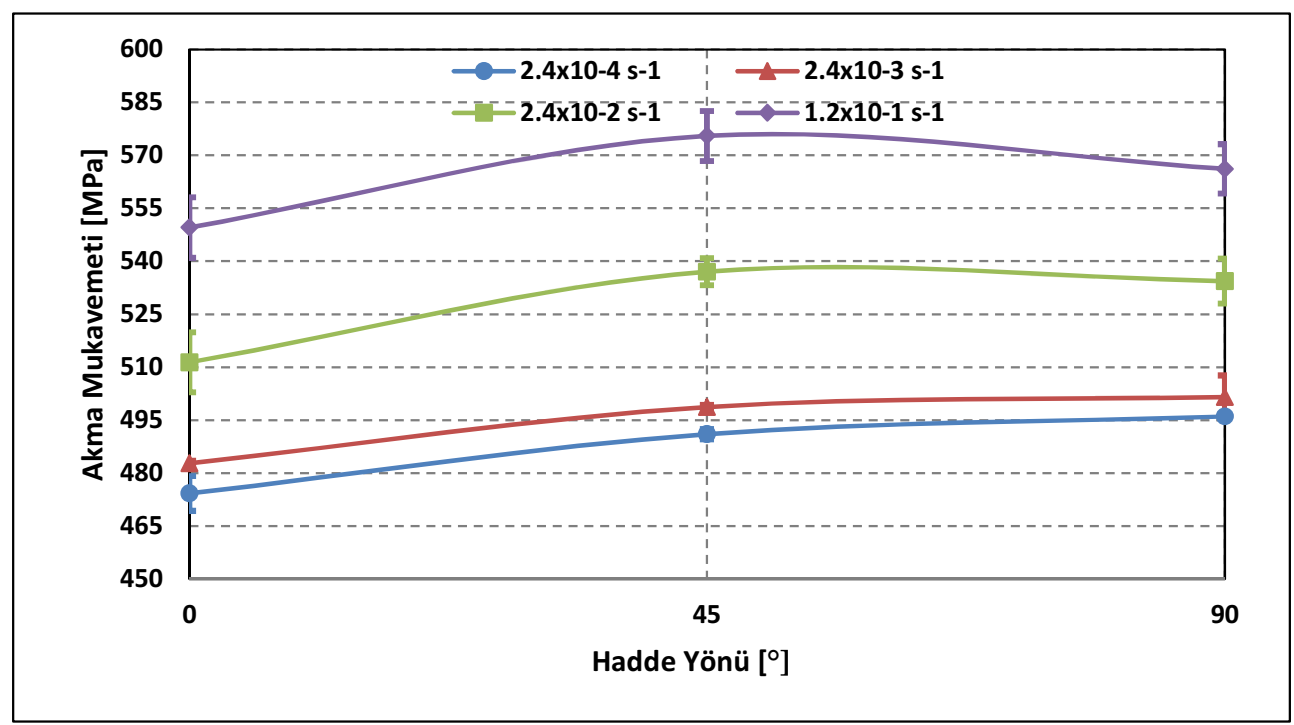

Şekil 13. Farklı deformasyon hızlarında DP800 çeliğine ait numunelerde akma mukavemetinin hadde yönü ile değişimi.

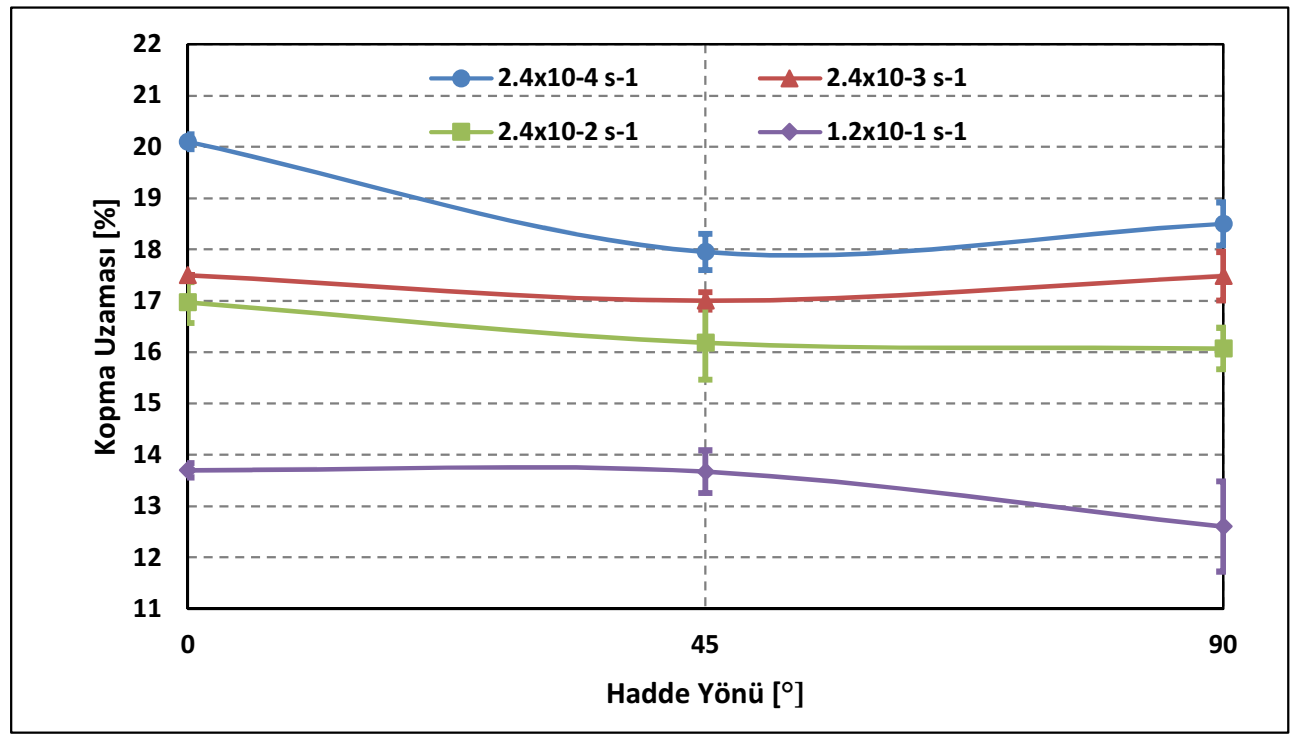

Şekil 14. Farklı deformasyon hızlarında DP800 çeliğine ait numunelerde kopma uzamasının hadde yönü ile değişimi.

\section{Genel sonuçlar}

Bu çalışmada, çift fazlı DP450 ve DP800 çeliklerinde deformasyon hızının ve haddeleme yönünün çekme özellikleri üzerindeki etkisi incelenmiştir. Yapılan deneysel çalışmalar sonucunda elde edilen sonuçlar aşağıdaki gibi özetlenebilir:

- DP450 ve DP800 çeliklerinde deformasyon hızındaki artış ile beraber akma ve çekme mukavemetleri artmakta fakat yüzde uzama değerleri önemli oranda düşmektedir. Her iki çelikte de deformasyon hızının akma mukavemeti üzerindeki etkisi çekme mukavemeti üzerindeki etkisinden daha fazladır.

- DP800 çeliğinde deformasyon hızı ile mukavemet artış oranı DP450 çeliği ile karşılaştırıldığında nispeten daha düşüktür. Ancak, DP800 çeliğinde deformasyon hızının kopma uzaması üzerindeki etkisi DP450 çeliğinkinden daha fazla olmuştur. 
- Genel olarak, DP450 ve DP800 çeliklerinde $45^{\circ}$ hadde yönünde nispeten daha yüksek mukavemet değerleri gözlenirken aynı hadde yönünde daha düşük uzama değerleri elde edilmiştir.

- DP450 ve DP800 çeliklerinde deformasyon hızının çekme özellikleri üzerindeki etkisi hadde yönü etkisinden daha fazla olmuştur.

\section{Kaynaklar}

[1] Salamcı, E., Kabakcı, F., Çift fazlı çeliğin çekme özelliklerine mikroyapının etkisi, Gazi Üniveristesi Mühendislik Mimarlık Fakültesi Dergisi, 26(2), 263272, (2011).

[2] Çetinel, H., Çift fazlı çeliklerde şekil alabilirlik, DEÜ Mühendislik Fakültesi Fen ve Mühendislik Dergisi, 6(2), 73-80, (2014)

[3] Bag, A., Ray, K. K. and Dwarakadasa, E. S., Influence of martensite content and morphology on tensile and impact properties of high-martensite dual-phase steels, Metallurgical and Materials Transactions A, 30(5), 1193-1202, (1999).

[4] Cadoni, E., Singh, N. K., Forni, D., Singha, M. K. and Gupta, N. K., Strain rate effects on the mechanical behavior of two Dual Phase steels in tension, The European Physical Journal, 225(2), 409-421, (2016).

[5] Chen, H., Xu, X., Xu, W. and Van Der Zwaag, S., Predicting the austenite fraction after intercritical annealing in lean steels as a function of the initial microstructure, Metallurgical and Materials Transactions A, 45(4), 16751679, (2014).

[6] Ahmad, E., Manzoor, T., Ziai, M. M. A. and Hussain, N., Effect of martensite morphology on tensile deformation of dual-phase steel, Journal of Materials Engineering and Performance, 21(3), 382-387, (2012).

[7] Padmanabhan, R. , Baptista, A. J., Oliveira, M. C. and Menezes, L. F., Effect of anisotropy on the deep-drawing of mild steel and dual-phase steel tailor-welded blanks, Journal of Materials Processing. Technology, 184(1-3), 288-293, (2007).

[8] Huh, J., Huh, H. and Lee, C. S., Effect of strain rate on plastic anisotropy of advanced high strength steel sheets, International Journal of Plasticity, 44, 23-46, (2013).

[9] Demirci, A. H., Malzeme Bilgisi ve Malzeme Muayenesi, Alfa Aktuiel Yayınları, (2004).

[10] Yu, H., Guo, Y. and Lai, X., Rate-dependent behavior and constitutive model of DP600 steel at strain rate from $10^{-4}$ to $10^{-3} \mathrm{~s}^{-1}$, Materials Science \& Engineering A, 30(7), 2501-2505, (2009).

[11] Kim, J. H., Kim, D., Han, H. N., Barlat, F. and Lee, M. G., Strain rate dependent tensile behavior of advanced high strength steels: Experiment and constitutive modeling, Materials Science \& Engineering A, 559, 222-231, (2013).

[12] Curtze, S., Kuokkala, V. T., Hokka, M. and Peura, P., Deformation behavior of TRIP and DP steels in tension at different temperatures over a wide range of strain rates, Materials Science \& Engineering A, 507(1-2), 124-131, (2009).

[13] A. American and N. Standard, Practices for test methods for evaluating the resistance spot welding behavior sheet steel recommended practices for test methods for evaluating the resistance spot welding behavior of automotive sheet materials, American Welding Society, (2002). 